\title{
Niche level investment challenges for European Green Deal financing in Europe: lessons from and for the agri-food climate transition
}

\author{
Thomas B. Long (10) ${ }^{1 凶} \&$ Vincent Blok ${ }^{2}$
}

Green New Deal (GND) policies are proposed to tackle the climate emergency. These policies focus on driving climate innovation through unprecedented financial policy levers. However, while the macro-level financing dynamics are clear, the influence of niche level dynamics of sustainable innovation financing remain unexplored within these policy settings. Through the context of the European Green Deal and a focus on the agri-tech start-up sector in the Netherlands, we identify factors likely to reduce the efficacy of these policies from an innovation management perspective-such as project matching issues, socio-ethical factors or the characteristics of agri-food climate innovations. We go on to conceptualise that these challenges represent a range of asymmetries-from classic information asymmetries to less common value and objective asymmetries-between climate innovators and private investors and financers. Many remedies for asymmetries involve costs, likely to further inhibit the efficacy of the European Green Deal and similar policies. A partnering approach is proposed, where the non-financial resources of incumbent actors are harnessed and leveraged to enhance climate innovation performance.

\footnotetext{
${ }^{1}$ Centre for Sustainable Entrepreneurship, Campus Fryslân, University of Groningen, Leeuwarden, The Netherlands. ${ }^{2}$ Philosophy Group, Wageningen University, Wageningen, The Netherlands. ${ }_{\text {email: T.b.long@rug.nl }}$
} 


\section{Introduction}

reen New Deal approaches emerged in the wake of the 2008 financial crisis and have been gaining traction from the United States to China as a response to the climate crisis (European Commission, 2019; Jacobson et al., 2015; Pettifor, 2019). At their core, Green New Deal (or alternatively Green Deal) approaches seek drastic reductions in greenhouse gas emissions with time sensitive targets to protect and restore ecosystems (Jacobson and Delucchi, 2009). These policies argue for high levels of state intervention to stimulate the required climate orientated transition, especially within carbon intensive sectors. State intervention focuses on enhancing capital flows to priority sectors, through public and private investment. In line with these ideas, the EU announced a 'European Green Deal' in late 2019, with the aim of climate neutrality by 2050 (European Commission, 2020b). This will involve the development of climate-oriented technological innovations, from idea generation, and demonstration, through to diffusion and mobilisation.

Transition theories offer a valuable perspective for the changes that are needed for the European Green Deal and similar approaches to achieve their goals. The Multi-level perspective (MLP), for instance, highlights how new, radical and pathbreaking technological innovations-needed to tackle the climate crises-emerge in protected niches, and if successful, make their way to the regime, which represents the mainstream or status quo (Geels and Schot, 2007, 2010). The regime can be influenced by high level trends that occur above, in the 'Landscape'. For a technology to 'break through' into a regime, either the niche must adjust to better align with the existing regime-'fit and conform'-or the regime changes to better align with the niche, where key aspects of the niche (i.e., new norms) are transferred to the regime-termed 'stretch and transform' (Lauber and Jacobsson, 2016; Smith and Raven, 2012).

Sustainability transitions, such as the one sought through the European Green Deal, are influenced by many factors, including policy, the stance of incumbent actors, or niche-regime interactions (Geels and Schot, 2010). It is argued that a core constraint for current climate innovations is insufficient levels of innovation financing at the niche level (Cecere et al., 2018). Financing plays a key role in deciding which technologies are successful and able to make the jump from niche to regime diffusion (Dosi, 1990). Innovations face two particularly challenging moments in terms of financing-known as valleys of death-including the move from demonstration to commercialisation and then again when scaling towards widespread usage (Karltorp, 2016; Nemet et al., 2018).

We already know that sustainable innovations, including climate orientated innovations, are treated differently by investors, for example, due to their pro-environmental and pro-social goals, which go beyond standard economic aims (Cillo et al., 2019). Yet given the role of financing in sustainability transitions, it is somewhat of a blind spot in transitions research and theory, with only limited sector specific research (for instance on the renewable energy transition). For example, research has previously explored regime niche interactions and how State Investment Banks can enhance financing (Geddes and Schmidt, 2020). This lack of knowledge could have implications for European Green Deal and similar policies.

In this research we seek to fill the knowledge gap of how niche level dynamics will affect the efficacy of the European Green Deal by researching the case of innovation financing of agri-tech startups. Research on the European Green Deal from an economic, policy and governance perspective is evident, however, we take an innovation management perspective to shed new light on key factors and dynamics. In doing so, we answer the research question: How are niche level financing dynamics likely to impact the efficacy of the European Green Deal. Identifying and analysing these dynamics will improve the management and design of Green New Deal style policies. We take a sectoral focus, exploring the issues within the context of the European agri-food sector, and in doing so expand existing research on transitions theory and financing to a new sector (i.e., Geddes and Schmidt, 2020).

\section{The European Green Deal and the agri-food sector}

The European Green Deal commitment to develop a carbon neutral economy has major implications for the agri-food sector (Climate-KIC, 2020), such as shifting to an organic-based circular economy, reducing chemical pesticide usage, and improving animal welfare. This transition to a sustainable food system will be tackled through, on the one hand, innovation and research drivers, and on the other, advisory and knowledge support services aimed across the value chain. As such, innovation plays a core role in this sustainability transition through investment in modernisation, digitalisation and optimisation efforts, the scale of which is likely to strain current financial sources. Moreover, this is where the European Green Deal (as with other Green New Deal style policies) targets much of its fire power.

The European Green Deal seeks to change how the financial system (regime) allocates capital and manages (green) investments for innovative projects and businesses (Akcigit and Kerr, 2018; Barbier, 2010; Kerr and Nanda, 2014; Pettifor, 2019). These policies try to encourage investment strategies that internalise environmental costs as financial risks, as opposed to externalising these risks, which is the standard approach for most financing strategies. Investment strategies must also overcome the 'tragedy of the horizon', better aligning long-term climate challenges with the often short-term approaches of investors and financial policymakers (Carney, 2015). These issues are tackled through de-risking, securitisation and hedging techniques (European Commission, 2020b; World Bank, 2018), all designed ${ }^{1}$ to release and harness private funds and resources (Herics et al., 2018). At the micro level, this means investors will have to incorporate additional non-economic criteria into investment decisions, and invest in different types of projects, incorporating climate change and additional socioethical objectives, to an unprecedented degree. While many of the macro and meso (regime) level processes of the European Green Deal are clear-focusing on de-risking and leveraging private funds-niche level factors, such as transaction cost effects and the behavioural impacts on climate innovators and financial institutions, are less understood, which raises questions for policy efficacy.

\section{Innovation and its financing for the climate crisis}

Innovation activities are predominantly carried out at the niche level within networks of individual firms. Many innovation and commercialisation activities are undertaken by start-up companies, due to their innovativeness, flexibility, and their high-risk appetites (Loorbach andand Wijsman, 2013; UNECE, 2016). These firms are typically financed through debt financing, often through commercial banks, soft loans from governments, or equity funding through venture capital and informal investments (Marlow and Patton, 2005). This has provided insufficient financing to unlock the potential of these firms to meaningfully help tackle the climate crisis. Agri-food 
climate innovations have to a large extent only had access to niche financial markets and specialist investors (Bergset, 2015), as mainstream financial markets are set up to assess and serve orthodox, economically focused start-ups and projects (Gast et al., 2017).

There are several explanations for why climate innovations are assessed differently to 'normal' innovations within the current growth orientated neo-classical regime. For instance, some explanations focus on issues faced by investors. As part of the regime, they lack the expert knowledge needed to assess novel climate innovations, which increases transaction costs, making these investments relatively more expensive and riskier, reducing their attractiveness (Mazzucato, 2013). The problem here, is that the longer time frames needed for sustainable innovation are incompatible with the demand for short-term returns by venture capital. Larger innovating firms overcome these issues by falling back on their established balance sheets, yet it is the smaller startups that are likely to come up with the needed innovations. Demand side factors are also observable. It has been found that many 'green' start-ups have poor knowledge and awareness of investor requirements and of the financial markets in general (Bergset, 2018). The 'mission' climate innovations seek to address is argued to be different from those of the past, also (Mazzucato and Penna, 2016). Putting a man on the moon had a clearer technological need and demand compared to the technological and wider system innovations needed to reduce carbon emissions and tackle climate change. The required technological solutions are likely to require long-term commitments and will be developed during continued technological and institutional change.

By taking a MLP perspective, Geddes and Schmidt (2020), highlight factors that impact the interaction between niche level innovation actors and financial actors within the regime. Overall, they found a range of reasons for why financial flows to sustainable niches were limited. They identified factors known previously, such as risk levels, transaction size and knowledge levels. They also highlighted that the absence of an industry network, such as supply chain partners, manufacturers, or insurers as relevant. Most interestingly, they explored how interventions by State Investment Banks could help enhance financing, such as industry coordination, de-risking, capital aggregation and education of both financiers and entrepreneurs. While this research is informative it did not explicitly consider the dynamics operating within the context of Green New Deal style policies, such as the European Green Deal.

In this article we build upon previous research exploring sustainability transitions and financing to provide more detail on key niche level factors likely to influence European Green Deal efficacy, and what additional measures could be needed to enhance the impact and likelihood of success of these types of policies. The research is based on unique access to 17 financial experts with knowledge and experience of financing agri-food climate innovations in the Netherlands, and covers the whole innovation process, from ideation through to commercialisation.

\section{Methods}

For this study, we took a qualitative and inductive approach for several reasons. Firstly, the question of how sustainability transition financing operates at the niche level of innovation management for transitions studies is understudied, requiring exploratory research and a flexible research approach. While the topic of 'green' innovation financing and start-ups is covered in the literature, this is all within the current 'status quo' context, where the financing of these types of projects is limited to specialist investors. Our question concerns the implications of the application of a European Green Deal where de-risking, securitisation and hedging techniques increase the flow of financing to the niche level.

Secondly, our questions have a 'how' and 'why' focus. How will increased financing at the niche level work and why? And how can the efficacy of these types of policies be enhanced through an understanding of niche level dynamics. These types of questions are not easily answered through surveys or modelling, given the number of potential variables and the uncertainty. Instead, we rely on the use of a combination of expert knowledge and opinion, collected through interviews as well as secondary data sources, providing rich data from a wide variety of different perspectives, on both the demand and supply side of innovation and start-up financing.

Case selection. To explore our question of niche level financing dynamics and their impact of the efficacy of the European Green Deal, we focus on the case of 'agri-tech' start-ups in the Netherlands. We explore the Dutch agri-tech start-up sector as a case with both typical and extreme elements (Seawright and Gerring, 2008). At a European sectoral level, like many other sectors, the development and diffusion of technological innovations is expected to play a key role the in agri-food industry's contribution towards the aims of the European Green Deal-a climate neutral continent (European Commission, 2020a; Seawright and Gerring, 2008). As in other sectors, financing is identified as a key barrier to the development and diffusion of agri-tech innovations for sustainability within Europe at both the organisational and systems level (Long et al., 2016, 2019). Financing challenges are particularly pertinent for the start-ups most likely to develop the needed agri-tech innovations, due to a generally unsympathetic 'financing regime' (fi-compass, 2020). In this sense, our case is one that requires a substantial sustainability transition, where technological innovation will play a key role, and where financing challenges exist. As such, the agri-tech start-ups operating in the agri-food sector represent a set of typical challenges and have a good theoretical fit, incorporating key factors and dynamics (Seawright and Gerring, 2008).

Agri-food is a priority sector in the European Green Deal due to its high economic, societal, and environmental impacts. We explore the implications and efficacy of a European level policy-the European Green Deal-which will be applied in some ways by individual nation states through the Common Agricultural Policy (CAP). The CAP will apply the European Green Deal via the 'Farm to Fork' strategy, which focuses on sustainable food production, sustainable food processing and distribution, sustainable food consumption, food loss and waste prevention (European Commission, 2020a). At the public level, a focus on the Netherlands highlights an advanced agri-food and agri-tech innovation sector-where any financing or innovation challenges would be expected to be found in other contexts. Additionally, the design of the European Green Deal, which also seeks to influence and encourage private financing at a supra-national level through de-risking, leveraging and transparency policies (Government of the Netherlands, 2019), means national level dynamics are only somewhat applicable in terms of financing flows. Overall, we see a range of national characteristics in terms of the sector and its innovation capabilities, which represent a somewhat atypical and best-case scenario, accompanied with European level sector and financial regime factors, that are more typical.

Data collection. Our data was collected during 2016-2018 from both entrepreneurs attempting to launch agri-food climate innovations as well as a range of financial experts (see table). 
No. Interviewee

R1. Impact orientated Venture Capitalist Fund Partner

R2. Banker and Researcher

R3. Institutional Investor Investment Vehicle

R4. Financing Expert/ Academic

R5. Investment Management

R6. Impact orientated Venture Capitalist Fund Partner

R7. Specialist sustainability bank - Head of investing

R8. Start-up Incubator Manager

R9. Financing Expert/ Academic

R10. Pensions Industry expert and Academic

R11. Financing Expert/Academic

R12. Financing Expert/Academic

R13. Investor Trade Association Analyst

R14. Regional Development Agency Asset Manager

R15. Sustainable Innovation Fund Associate

R16. Alternative Financing Organisation Chairman

R17. National Development Bank Senior Specialist

All those interviewed were located within the Netherlands. While based in the Netherlands, most participants were involved in projects across Europe, enabling us to capture dynamics beyond the particular national context. These participants were selected based on their expertise and knowledge and included practicing investors and financiers covering a range of perspectives, experts, as well as climate entrepreneurs. Participants were identified through internet searches, and approached via email or telephone for an interview. All interviewees provided informed consent when participating in the study. This was facilitated via the provision of information sheets that outlined their rights and responsibilities as research participants and was followed by a requirement to sign consent forms, in line with research ethics norms.

The interviews covered (1) the background and orientation of the interviewee, (2) their perspective on climate issues and socioethical factors and how they impacted financial and investment decisions, (3) the extent to which these factors could be taken into account in investment decisions and processes, (4) what would be needed for financiers and investors to play a greater role in climate innovation, and (5) the responsibilities of other systems actors. On average each interview lasted about 50 minutes. The interviews were then transcribed and coded by the first author.

We collected data until data saturation was reached, in line with the qualitative research approach (Corbin and Strauss, 1990); further, as our sample contained a diversity of respondents (a heterogenous group) a guide of around 20 interviews are thought to be necessary for data saturation (Morse, 1994). As our number is within this guidance, we are confident that the number of interviews was sufficient to justify the conclusions we reach.

Data analysis. Data analysis started with the production of the interview transcripts. Based on the reviewed literature and concepts, we sought to identify key factors operating at the level of niches within a MLP perspective, that were likely to impact the efficacy of Green New Deal type policies, such as the European Green Deal. To do this, we took an inductive approach, where the transcripts were read and any mentions of factors relevant to niche level dynamics being noted and codes assigned (Corbin and Strauss, 1990). These gradually formed the 1st order codes shown, and through an iterative process of trying to identify similarities and differences within the initial codes, the $1^{\text {st }}$ order codes were further refined. The coding process started as a 'data' led process, allowing the informant and expert content to lead, maintaining the 'voice' of the interviewee's knowledge and experience. Following the development of the codes, concepts were developed to represent the factors that we identify as impacting the efficacy of Green Deal style policies. Triangulation was attempted where possible, using grey literature and internet searches, to gain additional understanding.

For example, a key theme picked up within the interviews was a noted frustration by many investors that while they often had capital to invest, a challenge lay in finding enough projects of sufficient quality to invest in. In several interviews, the respondents highlighted issues around both quantity and quality, with low levels of viability and commercialisation potential. As shown in Fig. 1, these two issues around levels of viability and commercialisation potential were formed into two separate codes. Through the above noted iteration process to refine and create mutually exclusive themes, these two codes formed the theme 'poor venture supply'.

\section{Results}

We explore how a range of niche level factors are likely to affect the efficacy of the European Green Deal for the agri-food sector. We identify dynamics operating at the niche level, interacting with financiers within the regime. We assert that these factors will impact the ability of the European Green Deal and similar policies to meet their targets. We examine each theme individually below.

Project matching. A key challenge was the matching of innovation projects with investors. Investors often look for specific project profiles or niches. Agri-food climate innovations constitute a new emerging sector where investor networks are still developing. Our data indicated barriers related to project matching. While some existing specialist investors play a facilitative role, however, there are questions over whether they have the capacity needed within a European Green Deal context:

That is why there is a whole eco-system of $\mathrm{VC}$ and private equity firms that help the institutional investors to get involved in such small innovation projects (R3).

Additional facilitation and coordination could be required as financing for agri-food climate innovation is ramped up.

Information flows and metrics. The nature of niches and emergent technological innovations highlighted the issue of information flows between potential investors and innovators, creating another type of matching issue, relating to both financial and climate performance information.

Agri-food climate innovations are often radical in nature, creating uncertainties and ambiguities, making the gathering of information difficult. Even where an innovator 'claims' particular climate performance, it can be difficult to objectify for investors and users, especially as agri-food innovations often require several 'seasons' in which to establish claims. This type of information is different to the standard financial reporting figures often used to make investment decisions. This raises due diligence and information provision costs:

But in practice, it is sometimes not clear cut-sometimes we don't know what the company does exactly, sometimes we don't know what the consequences of their actions will be- which is very common. They often will not know themselves! (R7)

While information is harder to obtain, due to novelties, it is also harder to understand and interpret given a lack of available 


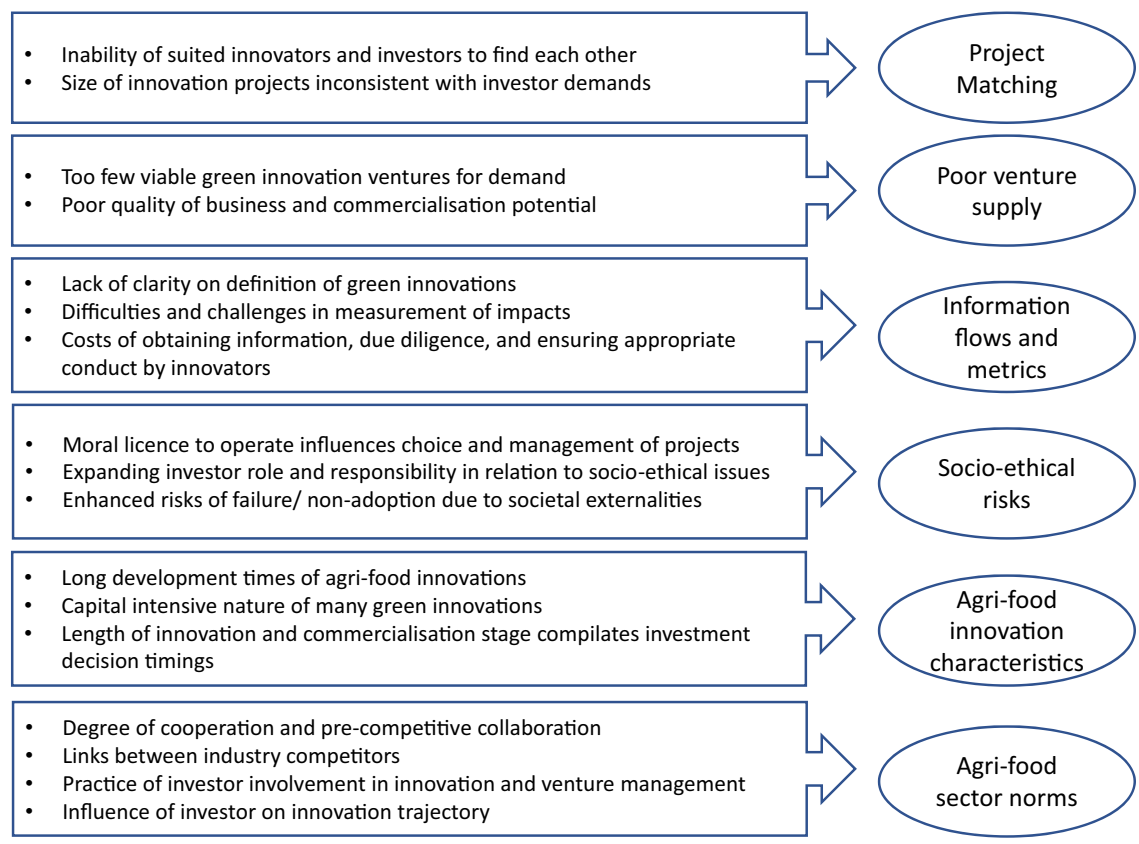

Fig. 1 Overview of Results. This figure highlights the 1st order codes that emerged through the data analysis and the subsequent 2 nd order themes.

and standard metrics. Assessing potential climate impact is no simple task, as noted by a specialist VC company:

We find it very difficult to calculate [impact] it and to monitor. I sometimes think but maybe it's not correct, it is easier to talk labour than to talk environmental impacts.... (R1)

Even specialist investors often have to rely on external experts, for instance, through impact committees:

Every investment we do, we have to get an advise of our impact committee which is with [variety of academic and third sector institutions] (R8)

Poor venture supply. Our data indicated that there was an overall poor venture and project supply, in terms of both quantity and quality. For example, one respondent highlighted how as an investor with strict 'deep green' requirements, they often found too few projects with the combination of climate impact and financial viability.

We have a problem in our business model in the sense that it is difficult to get the right projects for the deposits that we have. There is too much money coming in, from people interested in sustainability, and too few projects... The business plans are often not that good. Often, they have no clients-they are beautiful plans, but with no clients. They are too expensive, have no real value proposition, and so on, so, we won't finance it. (R7)

One reason for the low supply of projects was the limited levels of entrepreneurial competencies needed to commercialise the innovations. VC often counter this by requiring that a professional manager be involved. This enhances professionalism and helps counter information asymmetry issues and principal agent problems for the investors. However, it also involves additional costs, affecting the return-on-investment equation.

This highlights a need for the European Green Deal and similar type approaches to also focus on improving innovation and venture supply, ensuring minimum impact standards, linking to the issue of metrics above, ensuring a sufficient quality in terms of market viability and potential.

Socio-ethical risks. Socio-ethical risks emerged as potentially influential because agri-food climate innovations interact with and influence the environment and society. Socio-ethical risks covered ethical issues such as data privacy and governance, through to societal questions concerned with animal welfare, all of which can impact the pace of commercialisation and diffusion. This means additional factors must be taken into account and managed:

It's a technology that really could help feed the world. But if you mess up the communication, and don't take other stakeholders into account and their perspective, you'll be seen as the next Monsanto. (R6)

Typically, what we do, is that we look at the key risks and again I say the public perception and regulation can have a major impact on the success of some businesses. CRISPR example would be like this. So, if it goes in the wrong direction, then the investment won't be so successful. (R6)

In addition, the aim to contribute to the sustainability transition can create potential value-asymmetries for investors, who focus on return on investment. Investors may seek to trade a reduced climate impact for improved economic returns. This introduces a further set of factors investors must consider when making investment decisions for agri-food climate innovation. The agri-food and biotech sector may be ahead of the game in this regard, as investors are already engaging with these issues and learning to take socio-ethical issues into account and make judgements accordingly.

So, there are big normative pressures operating alongside other factors. You need a licence to act- and that moral pressure also applies in the agri-food sector. You are tapping so low into Maslow, it is about health and food, it's the future of the children. (R8) 
Agri-food innovation characteristics. The nature of the development process of many agri-food climate innovations could also present problems. For instance, these types of innovations often have long development times, in line with other green innovations, which affect the economics of investment decisions and associated risks.

The clean-tech start's usually take a long time to development, which means they are high risk. So, they have technology risk, but also the risk of a technology being accepted into society. You need very deep pockets-there is a lot of capital needed. (R12)

Yeah, you say it reduces the risk. I'm convinced of that. But it's a long-term investment, and that is always difficult. They are often very hard to prove-you often need to be an expert to prove it and understand it. And your short-term revenues are probably going to be lower as a result. So, the ROI is over a longer term-and costs come before the benefits. Which also reduces short-term revenues-people do work well over long time scales. (R11)

Many agri-food climate innovations aim beyond simple replacement by renewables, impacting markets, supply chains and even wider systems, which can create additional uncertainties and complexities, placing additional requirements onto investors.

Agri-food sector norms. Finally, the specific sector that agri-food climate innovations occur within are also likely to influence niche level dynamics. For instance, some sectors, as noted above, are more used to collaborative working and co-creation approaches, effecting how innovation is carried out and how different actors operate.

The time scale attracts certain types of investors. And this attracts a certain business culture. It is key. This is a sectoral and cultural issue. But there is also a totally different way of doing business in Europe. The management models contrast-between Europe versus Anglo-Saxon. Big businesses act differently. (R8)

\section{Discussion and conclusions}

The identification of insufficient levels of innovation financing as a key barrier to tackling the climate emergency is a key rationale behind the European Green Deal and similar policies. Techniques such as systematic leveraging as well as de-risking via securitisation and hedging techniques are proposed to enable the unlocking of private sources of investment that can then be channelled towards climate orientated innovations. This policy vision and its corresponding levers originate from a high, systems level perspective and focuses on enabling regime actors (financiers) to reorientate and redirect capital to agri-food climate innovations. While aspects of the policy aim at deployment, innovation development, from ideation through to commercialisation, is also signalled as playing a key role (European Commission, 2020b), which indicates innovation niches have an important part to play.

We focus our analysis on a lower level of the system-nichesand in doing so highlight factors that potentially impact the efficacy of Green New Deal style policies. We identify factors that are likely to reduce policy efficacy as well as those factors that may support Green New Deal policy efforts. By identifying these factors, operating at the niche level of innovation financing, we seek to contribute to the debate on the European Green Deal and similar policies in economies such as the US and China. We in effect seek to add a niche level of detail, which is currently not thoroughly covered in transitions literature nor in the policy debate around the European Green Deal. In the following section, we explore how current theoretical understanding of sustainability transitions and investment dynamics can provide additional insights to our results, after which, we provide recommendations and discuss limitations.

Multiple asymmetries and their affects. Many of our results indicate that asymmetries present key challenges for the European Green Deal and similar style policies. The role of information asymmetry is well established in investment and financing literature, via transaction cost economics (Nayyar, 1990). It has also previously been explored as a reason for why green innovations, like agri-food climate innovations, seem to receive an unfavourable assessment by investors even where projects provide sufficient returns on investment (Bergset, 2018).

Our analysis identifies asymmetry issues likely to impact green recoveries and European Green Deal type approaches seeking to spur climate innovation. Previous research on niche to regime financing dynamics identify some similar issues, including levels of acceptable risk, transaction size, knowledge and heuristics, and industry network (Geddes and Schmidt, 2020). The issues identified through our results in terms of project matching, information flows and metrics, socio-ethical risks, and sectoral dynamics all have aspects that can be linked to asymmetry dynamics and mismatches, related to classic information asymmetries (Akcigit and Kerr, 2018; Bergset, 2018; Kerr and Nanda, 2014), and less common position, value or objective asymmetries. Objectives and values-based asymmetries operate due to the tension between obtaining a financial return on investment versus generating climate impact look much like principle agent issues (Jensen and Meckling, 1979). Information asymmetries can act to make this worse, veiling the innovators or entrepreneurs' motives to collaborate or seek financing (Blok, 2018). Indeed, many climate innovators are likely to take on sustainable entrepreneurial characteristics, seeking to develop more than narrow economic value, but environmental, or climate value, as well.

Moving beyond asymmetries. Even with these asymmetries, some financing does reach agri-food climate innovation niches - just an insufficient amount to achieve current targets. Why do investors still finance such projects? This is explained through behavioural theories and the impact of extra-financial motivations, such as 'warm glow' explanations (Andreoni, 1990), the influence of stakeholders and society (Bonnet and Wirtz, 2011), or because investors may actually be 'satisficers', rather than 'optimisers' as usually assumed (Gilad et al., 1984). Specialist investors partly overcome the barriers we identify by having extra-financial objectives-which are often to have a wider, extra-financial, climate impact. These specialist investors are often financed by public or non-profit institutions. One example we found was the practice of universities funding VC to invest in the research and innovations coming out of their own labs. Within these contexts, the regime actors can be seen to be aligning more closely with niche norms and characteristics, and in this sense are taking on a 'stretch and transform' type adjustment where rules and institutions are adjusted to suit the innovation niche (Geddes and Schmidt, 2020; Smith and Raven, 2012).

Our results indicate the existence of multiple financial regimes. Geddes and Schmidt (2020) conceptualised the financial regime as a regime within itself, interacting with other regimes, such as industry or technological regimes. Our results can be 
conceptualised as indicating the existence of two or more financial regimes -one aligned to other 'mainstream' regime actors, and a smaller more specialist financial regime orientated towards climate innovation niches. The niche orientated financial regime already closes the gap to the niche through 'stretch and transform' approaches. These included strategies such as the use of external expert boards, assurance, or by narrowing the types of projects they consider to those with which they have expertise and knowledge (Cuadrado-Ballesteros et al., 2017). However, the results category 'information flows and metrics issues' highlights how these issues are still prevalent and likely to impact an expansion or mainstreaming of efforts, which still implies costs, reducing return on investment.

While our analysis finds examples where the issues we identify are overcome, conventional financing theory still highlights that profit-maximising investors will be unwilling to compromise their economic return on investment, and will see climate impact as an unnecessary add-on (Pasewark and Riley, 2010; Von Wallis and Klein, 2015). Behavioural explanations attempt to overcome these issues but are only applicable where investors have extra-financial motivations, which are able to offset the primacy of financial concerns. We posit that this situation is unlikely to be sufficient to make European Green Deal and similar policies effective. Indeed, these policies assume that large scale private financing can be brought to bear on the climate problem, however, given our results we question whether it is possible to incorporate such extra-financial criteria, identified as responsible for existing investment in climate or 'green' innovation, into large scale private investment decisions.

We propose that the European Green Deal faces epistemic issues, which emerge at the niche level-often in the form of asymmetries. The asymmetries identified here highlight how the problem in hand-financing for climate orientated innovation involves a series of mismatches and tensions, which we describe as information, objective and value-based asymmetries, which highlight distance between innovation niches and mainstream financial regime.

These structural and epistemic issues relate to several characteristics of the climate issue, and agri-food system challenges in particular, such as 1) the need for collaboration between a range of actors to reach and achieve solutions - such as between entrepreneurs and innovators, investors, consumers through to government; 2) interconnections with other issues and challenges, such as social and development issues, and 3) the information asymmetries and unequal distribution of information and knowledge. Many of these characteristics are recognised by the Keynesian thinking that informs policies such as the European Green Deal (Barbier, 2010), yet do not seem to be sufficiently incorporated into policy design.

The current weakness we see in the European Green Dealboth epistemic and structural -emerge between niches and financial regimes. Climate change necessitates the collaboration of many actors, as no single actor possesses or has access to sufficient information. This is seen in our results through a lack of information and expertise on the side of the investors, as well as a highlighting of insufficient quantity and quality of climate innovation-based ventures (information) on the side of the innovators. This wider lack of information has been previously termed an 'epistemic insufficiency' (Blok, 2018). What makes this even more challenging is that this insufficiency may not be solvable in a simple sense.

The European Green Deal partly attempts to realign and reconfigure investment markets to capture currently untapped private sources of investment and finance. Many existing solutions, from the use of external expert boards or assurance approaches raise costs, skewing the return-on-investment equation. While European Green Deal financing will increase capital flows, impacts will be inhibited by these factors. Previous research has highlighted a key role for state investment banks in enabling co-investment and the subsequent learning that results (Geddes et al., 2020; Geddes and Schmidt, 2020). Within the Dutch and wider EU agri-food sector, these dynamics could be enhanced due to industry characteristics such as the high levels of pre-competitive competition and an existing network of specialist investors. The use of these approaches could spread the enabling activities of specialist agri-food climate innovation finances to other financial regimes, and in doing so enable a 'stretch and fit' process to narrow the niche-regime gap. Through such efforts, the more 'partnership' style approaches to investment seen as best practice in some sectors of the economy could be broadened. Such an approach would be based less on numbers, stepping away from the classic Silicon Valley type approach. Here it is a partnership approach, both with corporate and formal equity funds, that would enable agri-food climate innovations and the sustainable entrepreneurs that pursue them to leverage the resources and expertise of larger organisations.

Concluding remarks. In this research, we provide recommendations for the European Green Deal and similar Green New Deal style policies and how they increase funding for innovation. We used a sustainable innovation and entrepreneurship financing lens to explore these issues, as previous research on Green New Deal style policies and financing of the European Green Deal had largely ignored this perspective. Our disciplinary approach may omit other important factors and issues, and multiple perspectives, including a formal policy evaluation perspective is needed to further substantiate the claims in our paper. Such approaches could offer more specific recommendations on how the European Green Deal could be adjusted to take account of the factors we identify and explore.

In terms of sectoral dynamics and their implications for the generalisability of the research, the agri-food sector can be characterised as generally risk adverse, slow to take-up and incorporate new agri-tech innovations, which may represent additional barriers compared to other sectors. However, our focus on the Netherlands-a leader in the agri-food sector and in terms of agri-tech innovation development and diffusion-means our case illustrates some-what best practice for innovation dynamics and financing in agri-food. Indeed, we argue that any barriers or challenges identified in the Dutch context are likely to be more profound when applied to other national settings. Even with a strong and well developed agri-tech sector, the Netherlands still experiences poor financing supply, dominated by specialists, limiting opportunities for the dispersal of additional funding and places limits on the ability of innovative start-ups to scale up their innovations (Verbeek et al., 2019).

Additional research should explore the dynamics we identify within other national contexts within Europe and beyond. Further, our study was undertaken between 2016 and 2018. In the intervening years, the price of some climate-oriented technologies has reduced with implications for affordability and adoption. This is especially true for renewable energy. We argue that the core dynamics and asymmetries we highlight are only impacted by technological advances and price reductions to a limited degree however. For instance, the asymmetry in aims between sustainable entrepreneurs and investors is still likely to operate, and while investors may now be more informed, the issue of information asymmetry has not been solved. Further, our research focused on the agri-food sector where European Green Deal financing focuses on innovation and research levers as well as the expansion of advisory services. In this sector, upstream 
development of technologies and practices for the transition to an organic-based circular economy is still needed. In other sectors, the dynamics may be different. For instance, within the renewable energy sector, the focus may to a greater extent be on implementation of existing technologies. In these contexts, our results have most relevance for upstream innovation financing for continued technology development.

The nature of the gap between niche and regime that we identify is likely to exist within socio-technical transitions in other contexts and we hope our findings improve the efficacy of climate innovation financing interventions more widely. Future research should broaden the sample and explore if and how these factors operate beyond the European context.

\section{Data availability}

The datasets generated during and analysed during the current study are not publicly available due to concerns that participant confidentiality and privacy could be compromised.

Received: 24 November 2020; Accepted: 18 October 2021; Published online: 16 November 2021

\section{Note}

1 See Herics et al. (2018) for comment on the current evidence base for the success of such policies.

\section{References}

Akcigit U, Kerr WR (2018) Growth through heterogeneous innovations. J Polit Econ 126(4):1374-1443

Barbier E (2010) How is the Global Green New Deal going? Nature 464(7290):832-833. Psychology and Behavioral Sciences Collection

Bergset L (2015) The rationality and irrationality of financing green start-ups. Admin Sciences 5(4):260-285

Bergset L (2018) Green start-up finance-where do particular challenges lie? International Journal of Entrepreneurial Behavior \& Research

Blok V (2018) Information asymmetries and the paradox of sustainable business models: towards an integrated theory of sustainable entrepreneurship. In Moratis L, Melissen, F, \& Idowu SO (eds.), Sustainable Business Models (pp. 203-225). Springer International Publishing. https://doi.org/10.1007/978-3319-73503-0_10

Bonnet C, Wirtz P (2011) Investor type, cognitive governance and performance in young entrepreneurial ventures: a conceptual framework. J Acad Behav Finan $1(1): 4-6$

Carney M (2015, September 29). Breaking the tragedy of the horizon- climate change and financial stability [Speech at Lloyd's of London]. https:// www.bis.org/review/r151009a.pdf

Cecere G, Corrocher N, Mancusi ML(2018) Financial constraints and public funding of eco-innovation: empirical evidence from European SMEs. Small Bus Econ 54:1-18

Cillo V, Petruzzelli AM, Ardito L, Del Giudice M (2019) Understanding sustainable innovation: a systematic literature review. Corp Soc Responsib Environ Manag 26(5):1012-1025. https://doi.org/10.1002/csr.1783

Climate-KIC (2020) What's new for the agrifood sector with the European Green Deal? EIT. https://spain.climate-kic.org/en/news/whats-new-for-the-agrifoodsector-with-the-european-green-deal/

Corbin J, Strauss A(1990) Grounded theory research: procedures, canons, and evaluative criteria. Qual Sociol 13:3-21

Cuadrado-Ballesteros B, Martínez-Ferrero J, García-Sánchez IM (2017) Mitigating information asymmetry through sustainability assurance: The role of accountants and levels of assurance. Int Bus Rev 26(6):1141-1156. https:// doi.org/10.1016/j.ibusrev.2017.04.009

Dosi G (1990) Finance, innovation and industrial change. J Econ Behav Organ 13(3):299-319

European Commission (2019) Communication from the Commission to the European Parliament, The European Council, The Council, The European Economic and Social Committee and the Committee of the Regions: The European Green Deal (Communication $\operatorname{COM}(2019) 640$ final). European Commission

European Commission (2020a) Farm to Fork Strategy. https:/ec.europa.eu/food/ horizontal-topics/farm-fork-strategy_en
European Commission (2020b) Financing the green transition [Text]. European Commission-European Commission. https://ec.europa.eu/commission/ presscorner/detail/en/ip_20_17

fi-compass (2020) Financial needs in the agriculture and agri-food sectors in the Netherlands [Study Report]. European Commission \& European Investment Bank. https://www.fi-compass.eu/sites/default/files/publications/financial_ needs_agriculture_agrifood_sectors_Netherlands.pdf

Gast J, Gundolf K, Cesinger B (2017) Doing business in a green way: A systematic review of the ecological sustainability entrepreneurship literature and future research directions. J Clean Prod 147:44-56. https://doi.org/10.1016/ j.jclepro.2017.01.065

Geddes A, Schmid N, Schmidt TS, Steffen B (2020) The politics of climate finance: Consensus and partisanship in designing green state investment banks in the United Kingdom and Australia. Energy Res Soc Sci 69:101583

Geddes A, Schmidt TS (2020) Integrating finance into the multi-level perspective: Technology niche-finance regime interactions and financial policy interventions. Res Policy 49(6):103985

Geels FW, Schot J (2007) Typology of sociotechnical transition pathways. Res Policy 36(3):399-417. https://doi.org/10.1016/j.respol.2007.01.003

Geels FW, Schot J (2010) The dynamics of transitions: A socio-technical perspective. Transitions to sustainable development: new directions in the study of long term transformative change, 11-104

Gilad B, Kaish S, Loeb PD(1984) From economic behavior to behavioral economics: The behavioral uprising in economics. JBehav Econ 13(2):3-24

Government of the Netherlands (2019) Dutch reflection on the European Green Deal

Herics O, Obermayr T, Puricella P, Grassi E, Fara G (2018) Public Private Partnerships in the EU: Widespread shortcomings and limited benefits. European Court of Auditors, 79

Jacobson MZ, Delucchi MA (2009) A path to sustainable energy by 2030. Sci Am 301(5):58-65

Jacobson MZ, Delucchi MA, Bazouin G, Bauer ZA, Heavey CC, Fisher E, Morris SB, Piekutowski DJ, Vencill TA, Yeskoo TW (2015) $100 \%$ clean and renewable wind, water, and sunlight (WWS) all-sector energy roadmaps for the 50 United States. Energy Environ Sci 8(7):2093-2117

Jensen MC, Meckling WH (1979) Theory of the firm: managerial behavior, agency costs, and ownership structure. In Economics social institutions (pp. 163-231). Springer

Karltorp K (2016) Challenges in mobilising financial resources for renewable energy - The cases of biomass gasification and offshore wind power. Environ Innov Societ Trans 19:96-110

Kerr W, Nanda R (2014) Financing innovation (NBER WORKING PAPER SERIES). NATIONAL BUREAU OF ECONOMIC RESEARCH. https://wwwnber-org.proxy-ub.rug.nl/papers/w20676.pdf

Lauber V, Jacobsson S (2016) The politics and economics of constructing, contesting and restricting socio-political space for renewables-The German Renewable Energy Act. Environ Innov Societal Trans 18:147-163

Long TB, Blok V, Coninx I (2016) Barriers to the adoption and diffusion of technological innovations for climate-smart agriculture in Europe: Evidence from the Netherlands, France, Switzerland and Italy. J Clean Product 112:9-21. https://doi.org/10.1016/j.jclepro.2015.06.044

Long TB, Blok V, Coninx I (2019) The diffusion of climate-smart agricultural innovations: systems level factors that inhibit sustainable entrepreneurial action. J Clean Product 232:993-1004. https://doi.org/10.1016/ j.jclepro.2019.05.212

Loorbach D, Wijsman K (2013) Business transition management: Exploring a new role for business in sustainability transitions. J Clean Product 45:20-28. https://doi.org/10.1016/j.jclepro.2012.11.002

Marlow S, Patton D (2005) All credit to men? Entrepreneurship, finance, and gender. Entrepreneurship Theory Practice 29(6):717-735

Mazzucato, M. (2013). The Entrepreneurial State: Debunking Public vs. Private Sector Myths, 1

Mazzucato M, Penna CC (2016) Beyond market failures: The market creating and shaping roles of state investment banks. J Econ Policy Reform 19(4):305-326

Morse JM (1994) Critical issues in qualitative research methods. Sage

Nayyar PR (1990) Information asymmetries: a source of competitive advantage for diversified service firms. Strateg Manag J 11(7):513-519. JSTOR

Nemet GF, Callaghan MW, Creutzig F, Fuss S, Hartmann J, Hilaire J, Lamb WF Minx JC, Rogers S, Smith P (2018) Negative emissions-Part 3: Innovation and upscaling. Environ Res Lett 13(6):063003

Pasewark WR, Riley ME (2010) It'sa matter of principle: The role of personal values in investment decisions. J Bus Ethics 93(2):237-253

Pettifor, A. (2019). The Case for the Green New Deal. Verso

Seawright J, Gerring J (2008) Case selection techniques in case study research: A menu of qualitative and quantitative options. Polit Res Quar 61(2):294-308

Smith A, Raven R (2012) What is protective space? Reconsidering niches in transitions to sustainability. Res Policy 41(6):1025-1036 
UNECE (2016) Start-up nations: innovative entrepreneurship for sustainable development. https://www.unece.org/info/media/news/innovation/2016/startup-nations-innovative-entrepreneurship-for-sustainable-development/ doc.html

Verbeek A, Fackelmann S, McDonagh B (2019) Feeding future generations: How finance can boost innovation in agri-food. European Investment Bank (EIB) and European Commission (EC). https://www.eib.org/attachments/thematic/ feeding_future_generation_en.pdf

Von Wallis M, Klein C (2015) Ethical requirement and financial interest: A literature review on socially responsible investing. Bus Res 8(1):61-98

World Bank (2018) Maximizing Finance for Development (MFD) [Text/HTML].

World Bank. https://www.worldbank.org/en/about/partners/maximizingfinance-for-development

\section{Acknowledgements}

This research was supported by the Netherlands Organisation for Scientific Research (NWO), MVI programme. Number 313-99-319.

\section{Competing interests}

The authors declare no competing interests.

\section{Ethical approval}

All procedures performed in studies involving human participants were in accordance with standard ethical norms (1964 Helsinki Declaration and its later amendments or comparable ethical standards).

\section{Informed consent}

Participants were selected based on their expertise and knowledge and included practicising investors and financiers covering a range of perspectives, experts, as well as climate entrepreneurs. Participants were identified through internet searches, and approached via email or telephone for an interview. All interviewees provided informed consent when participating in the study. This was facilitated via the provision of information sheets that outlined their rights and responsibilities as research participants and was followed by a requirement to sign consent forms, in line with research ethics norms.

\section{Additional information}

Correspondence and requests for materials should be addressed to Thomas B. Long.

Reprints and permission information is available at http://www.nature.com/reprints

Publisher's note Springer Nature remains neutral with regard to jurisdictional claims in published maps and institutional affiliations.

cc) (i) Open Access This article is licensed under a Creative Commons Attribution 4.0 International License, which permits use, sharing, adaptation, distribution and reproduction in any medium or format, as long as you give appropriate credit to the original author(s) and the source, provide a link to the Creative Commons license, and indicate if changes were made. The images or other third party material in this article are included in the article's Creative Commons license, unless indicated otherwise in a credit line to the material. If material is not included in the article's Creative Commons license and your intended use is not permitted by statutory regulation or exceeds the permitted use, you will need to obtain permission directly from the copyright holder. To view a copy of this license, visit http://creativecommons.org/ licenses/by/4.0/.

(C) The Author(s) 2021 